\title{
The Roles of Acidity on Sono-Electrodeposition of Silver Nanoparticles
}

\author{
Kareem N. Abed ${ }^{1}$, Ahmed Q. Abdullah'1, Abdulkareem M. A. Alsammarraie ${ }^{2 *}$ \\ ${ }^{1}$ Physics Department, College of Science, University of Baghdad, Baghdad, Iraq \\ ${ }^{2}$ Department of Chemistry, College of Science, University of Baghdad, Baghdad, Iraq \\ Email: *samuraee2000@hotmail.com
}

How to cite this paper: Abed, K.N., Abdullah, A.Q. and Alsammarraie, A.M.A. (2018) The Roles of Acidity on Sono-Electrodeposition of Silver Nanoparticles. Materials Sciences and Applications, 9, 671-678.

https://doi.org/10.4236/msa.2018.98048

Received: March 31, 2018

Accepted: July 3, 2018

Published: July 6, 2018

Copyright (c) 2018 by authors and Scientific Research Publishing Inc. This work is licensed under the Creative Commons Attribution International License (CC BY 4.0).

http://creativecommons.org/licenses/by/4.0/

\begin{abstract}
The Ag NPs were produced by sonicating the electrochemical cell that the titanium horn serves as cathode and the anode was high purity silver foil, while the electrolyte in all experiments was $\left(0.2 \mathrm{~g} \mathrm{Ag}_{2} \mathrm{SO}_{4}\right.$ in $250 \mathrm{ml}$ deionized water), the $\mathrm{pH}$ was varied between 2 to 8 using sulfuric acid and sodium bicarbonate diluted solutions, the current density was maintained at $5 \mathrm{~mA} / \mathrm{cm}^{2}$. The quality of the products was extensively examined using: SEM, TEM, AFM, XRD, UV-visible and EDX techniques. The results reflected a clear fact that the more acidic electrolyte (lower $\mathrm{pH}$ value) has produced distorted spherical larger AgNPs, with a narrow particles size distribution, while decreasing the acidity (higher $\mathrm{pH}$ value) led to smaller particle size, and wider size distribution spectrum.
\end{abstract}

\section{Keywords}

Silver Sulfate, Silver Nanoparticles, Sonoelectrodeposition, AFM

\section{Introduction}

Sonoelectrochemistry is the coupling of ultrasonic vibration to an electrochemical system. The term "sonoelectrochemistry" appeared at 1990 [1]. Recently there is a growing interest of the application of the sonoelectrochemistry in the preparation of nanopowders [2] [3] due to it is environmental friendly and cost effectiveness method compared to most of other methods including radiation, thermal decomposition, and vapor deposition, reduction in microemulsions and chemical reduction [4]. Ultrasound has been applied in the fields of electroplating, electroorganic synthesis, electropolymerisation, electroanalytical chemistry and for the electrochemical production of nanoparticles [5]. Sonoelectrochemical formation of nanoscale metals was accomplished by applying an electric cur- 
rent pulse for electrodeposition, followed by a burst of ultrasonic energy that removes the particles from the son electrode [6]. The propagation of pressure waves in a fluid causes the formation of cavitation bubbles. At low irradiation intensity, these bubbles oscillate none linearly in the acoustic field. Above a threshold, called the transient cavitation threshold, the number of bubbles increases intensely. The collapse of these bubbles, described as an implosion in the hot-spot theory, or described as a fragmentation in the electrical theory, is at the origin of extreme local conditions: high temperature and high pressure following the hot-spot theory, high electrical fields following the electrical theory [7] [8]. When the irradiation intensity is higher than the threshold intensity, the collapse of the bubbles is also associated with shock waves and microstreaming. Mechanical effects including erosion of solids, fragmentation of solid particles in suspension and emulsification of non-miscible liquids can occur. Under the influence of these extreme local conditions and also of these mechanical effects, sonochemistry takes place. Sonochemistry, which is thus defined as chemistry induced by sound and ultrasound, is a fast developing field. It is well know that the final application highly depends on the particle size, in this work the particle size of $\mathrm{Ag} \mathrm{NPs}$ was tuned by variation of the $\mathrm{pH}$ of the $\mathrm{Ag}_{2} \mathrm{SO}_{4}$ electrolyte.

\section{Experimental}

Figure 1 show the experimental set-up used. In these experiments titanium probe $(20 \mathrm{kHz})$ acts both as a cathode and an ultrasound emitter. The electroactive part of the sonoelectrode is the planar circular surface at the bottom of the horn and the immersed cylindrical part into the electrolyte is covered by an isolating plastic jacket.

The ultrasound probe is connected to a power supply using a pulse driver. The system used the simplest configuration of a two-electrode cell, where the silver sheet used as anode. Before each experiment, the titanium sonoelectrode have been polished [9]. The electrochemical processes were performed at $\left(20^{\circ} \mathrm{C}\right)$, the temperature of the electrolyte maintained to within $\pm 1^{\circ} \mathrm{C}$ with cooling and

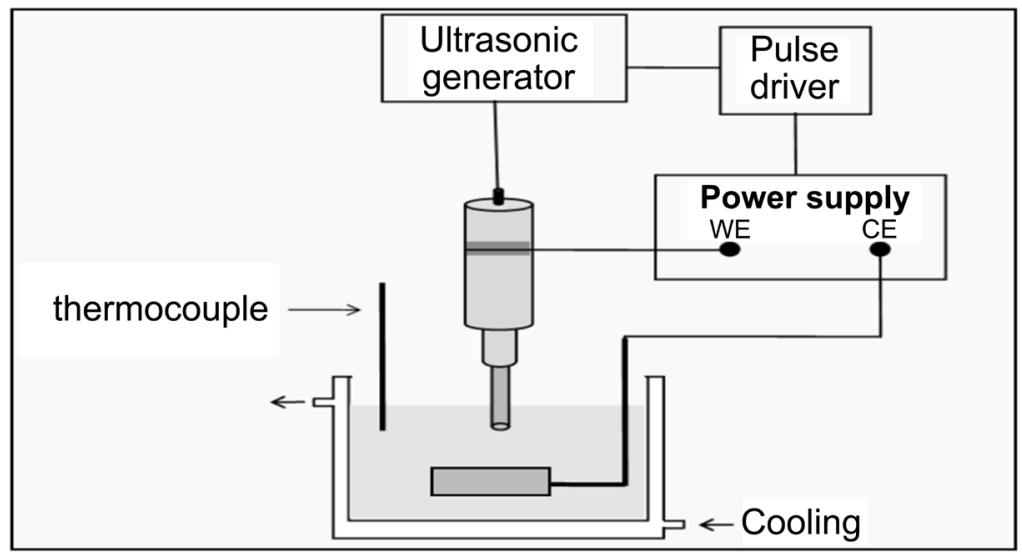

Figure 1. Sonoelectrochemistry set-up used in the production of nanopowders (WE working, and CE counter electrode). 
heating water bath circulator. The distance between the anode and cathode was $(30 \mathrm{~mm})$. The working time of $1 \mathrm{~min}$ was chosen, the electrolyte was $(0.2 \mathrm{gm}$ $\mathrm{Ag}_{2} \mathrm{SO}_{4}$, from Nanjing Chemical Reagent Co. in $250 \mathrm{ml} \mathrm{DI}$ ) and some drops of $\mathrm{H}_{2} \mathrm{SO}_{4}, 30 \mathrm{~W} / \mathrm{cm}^{2}$ ultrasound intensity and varying of $\mathrm{pH}$ value $(2,4$, and 8$)$. The silver foil was immersed in solution and using ultrasonic to obtaining silver nanoparticles. The produced AgNPs washed with distilled water and collected by Millipore nanofilter paper the characterized by atomic force microscopy (AFM), UV-visible spectra (UV-vis),Transmission electron microscopy (TEM) and $\mathrm{X}$-ray diffraction (XRD) techniques.

The electroactive part of the sonoelectrode is the planar circular surface with an area of $7 \mathrm{~cm}^{2}$ at the bottom of the horn. The immersed cylindrical part is covered by an isolating plastic jacket. A silver sheet $(2.0 \mathrm{~cm} \times 2.0 \mathrm{~cm})$ is used as a counter electrode.

\section{Results and Discussion}

SEM images in Figure 2, AFM images in Figure 3, and TEM images in Figure 4 reflected the effect of the electrolyte acidity $(\mathrm{pH})$ on the morphologies of the $\mathrm{Ag}$ NPs produced at current density of $\left(5 \mathrm{~mA} / \mathrm{cm}^{2}\right)$. These SEM and AFM images
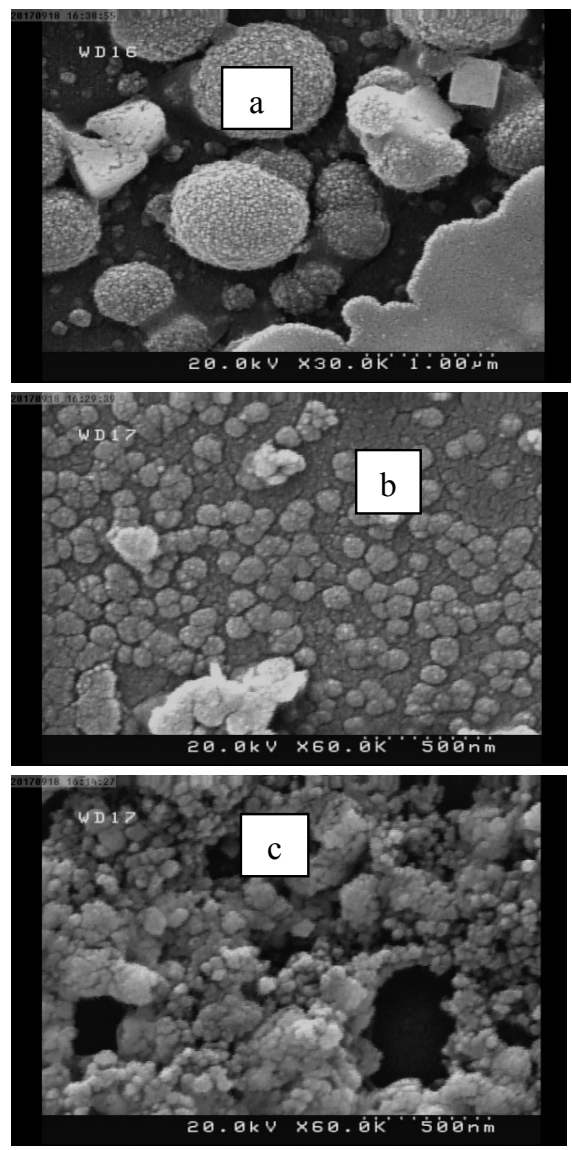

Figure 2. SEM images of Ag NPs produced by electrochemical sonication of $\mathrm{Ag}_{2} \mathrm{SO}_{4}$ electrolyte; (a) $\mathrm{pH} 2$; (b) $\mathrm{pH}$, and (c) $\mathrm{pH} 8$, all at $5 \mathrm{~mA} / \mathrm{cm}^{2}$ for $1 \mathrm{~min}$ with sonication power density of $30 \mathrm{w} / \mathrm{cm}^{2}$. 


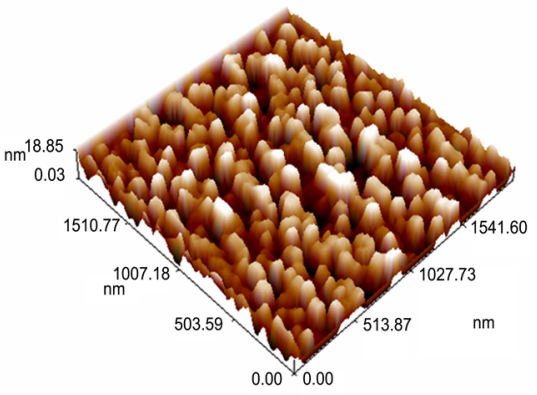

3D view (morphology)

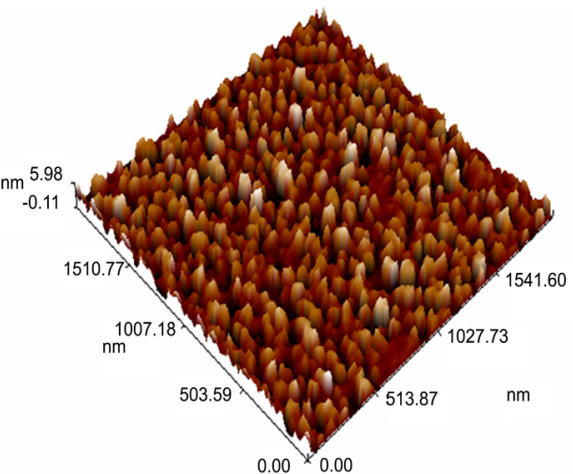

3D view (morphology)

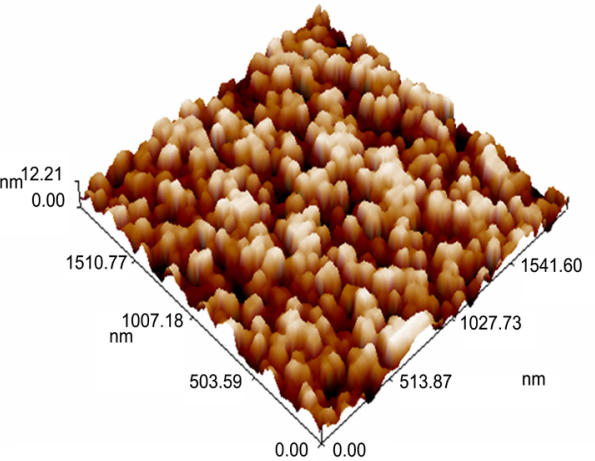

3D view (morphology)

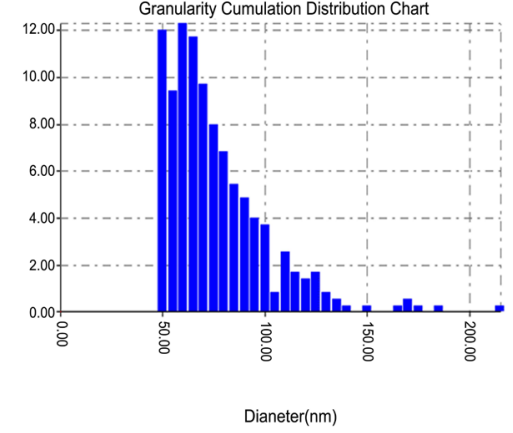

Particle size distribution

(a)

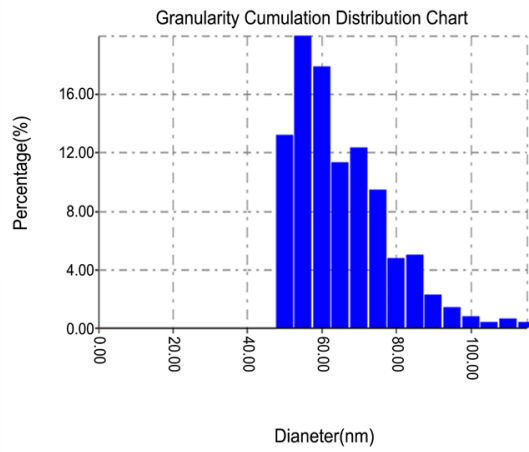

Particle size distribution

(b)

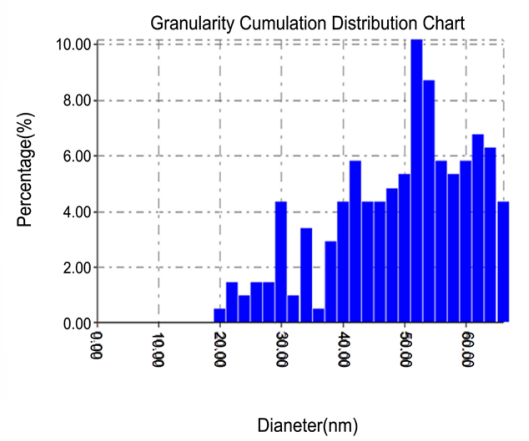

Particle size distribution
Sa(Roughness Average) 2.81 [nm] $\mathrm{Sq}$ (Root Mean Square) $3.27[\mathrm{~nm}]$ Ssk(Surface Skewness) -0.207 Sku(Surface Kurtosis) 1.91 Sy(Peak-Peak) 12.2 [nm] $\mathrm{Sz}$ (Ten Point Height) 12.2 [nm]

Roughness report
Amplitude parameters Sa(Roughness Average) $1.2[\mathrm{~nm}]$ $\mathrm{Sq}$ (Root Mean Square) 1.41 [nm] Ssk(Surface Skewness) 0.142 Sku(Surface Kurtosis) 2.02 Sy(Peak-Peak) 6.09 [nm] $\mathrm{Sz}$ (Ten Point Height) 6.01 [nm]

Roughness report
Sa(Roughness Average) 4.46 [nm] $\mathrm{Sq}$ (Root Mean Square) $5.22[\mathrm{~nm}]$ Ssk(Surface Skewness) -0.142 Sku(Surface Kurtosis) 1.93 Sy(Peak-Peak) 18.8 [nm] Sz(Ten Point Height) 18.8 [nm]

Roughness report

(c)

Figure 3. AFM images (3D, particles size distribution, and roughness reports) of Ag NPs produced by electrochemical sonication of $\mathrm{Ag}_{2} \mathrm{SO}_{4}$ electrolyte; (a) $\mathrm{pH}$; (b) $\mathrm{pH} 5$, and (c) $\mathrm{pH} 8$, all at $5 \mathrm{~mA} / \mathrm{cm}^{2}$ for $1 \mathrm{~min}$ with sonication power density of $30 \mathrm{w} / \mathrm{cm}^{2}$.

reflected a clear fact that the more acidic electrolyte (lower $\mathrm{pH}$ value) have produced distorted spherical larger AgNPs (around $73 \mathrm{~nm}$ ), with a narrow particles size distribution, while decreasing the acidity (higher $\mathrm{pH}$ value) led to smaller particle size (63 nm at $\mathrm{pH} 5$, and $48 \mathrm{~nm}$ at $\mathrm{pH} 8$ ), and wider size distribution spectrum. This manner may attributed to the lower repulsing forces between 

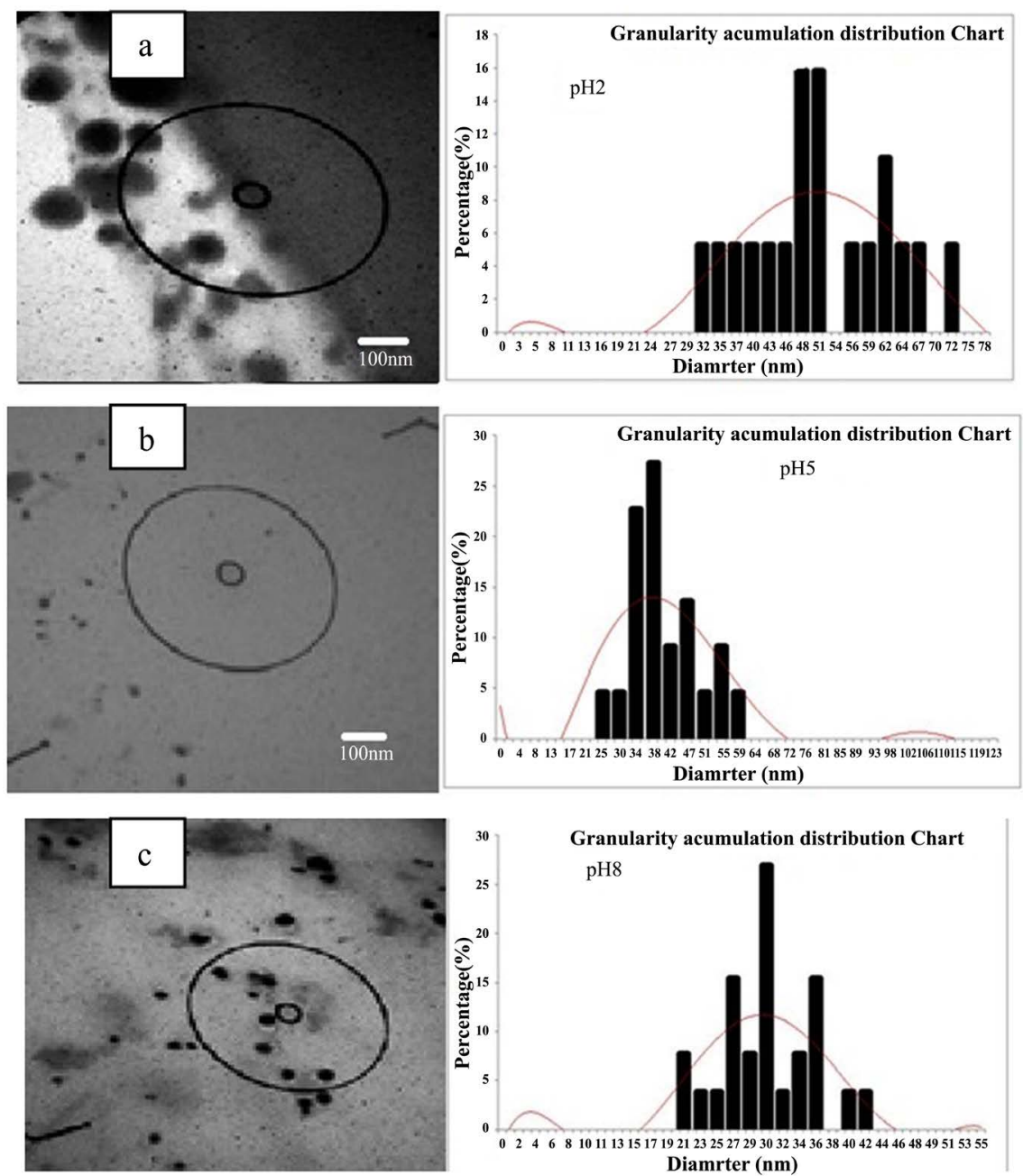

Figure 4. TEM images with granularity distribution of Ag NPs produced by electrochemical sonication of $\mathrm{Ag}_{2} \mathrm{SO}_{4}$ electrolyte; (a) $\mathrm{pH} 2$; (b) $\mathrm{pH} 5$; and (c) $\mathrm{pH} 8$, all at $5 \mathrm{~mA} / \mathrm{cm}^{2}$ for $1 \mathrm{~min}$ with sonication power density of $30 \mathrm{w} / \mathrm{cm}^{2}$.

partially positive charged Ag particles because of the more numbers of free cations in the more acidic electrolyte [9].

The decreasing of the particle size follows the order: $\mathrm{pH} 2(73 \mathrm{~nm})>\mathrm{pH} 5(63$ $\mathrm{nm})>\mathrm{pH} 8(48 \mathrm{~nm})$.

The particle surface roughness (SR) according to the AFM analyses shows unorganized manner, the lowest (SR) was recorded at $\mathrm{pH} 5(1.2 \mathrm{~nm})$ then at $\mathrm{pH} 8$ $(2.8 \mathrm{~nm})$, the higher value of (SR) was at $\mathrm{pH} 2(4.46 \mathrm{~nm})$.

Figure 5 shows UV-Visible absorption spectrum of the aqueous solution of the produced Ag NPs at different $\mathrm{pH}$ values, the peak at $400 \mathrm{~nm}$ is a specific peak of Ag-NPs, and can therefore confirm the formation of NPs in the solution due to the surface Plasmon resonance (SPR) of Ag NPs, the smaller size is, the broader the absorption band will be [10]. By increasing the $\mathrm{pH}$ value the absorbance peaks shift to higher wavelength (red shift) meaning lower energies, the absorbance vs wavelength has a red shift for smaller particles.

Figure 6 represent a typical XRD pattern of the produced silver nanoparticles 


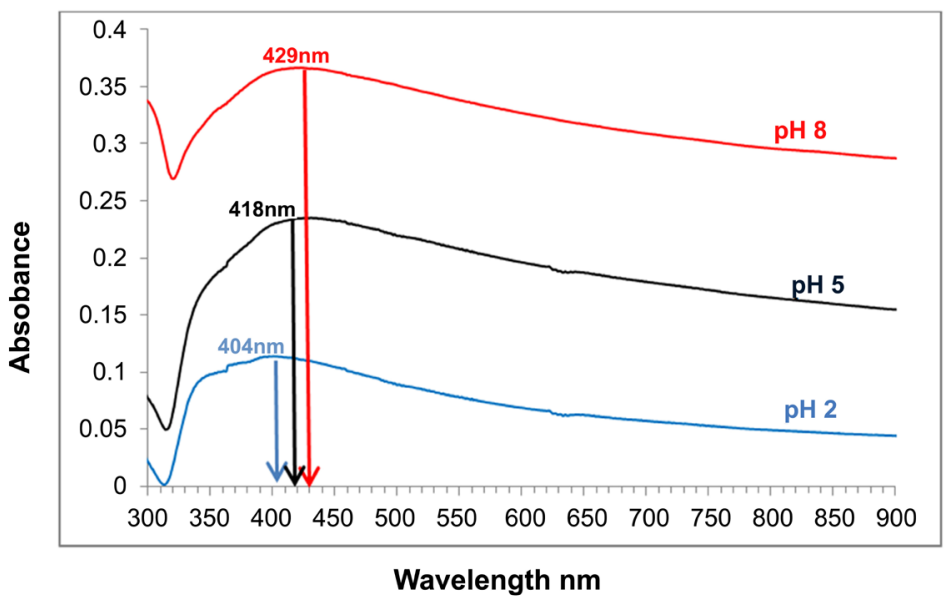

Figure 5. UV-VIS spectrums for AgNps synthesized by sonoelectrochemical of $\mathrm{Ag}_{2} \mathrm{SO}_{4}$ electrolyte at different $\mathrm{pH}$ value.

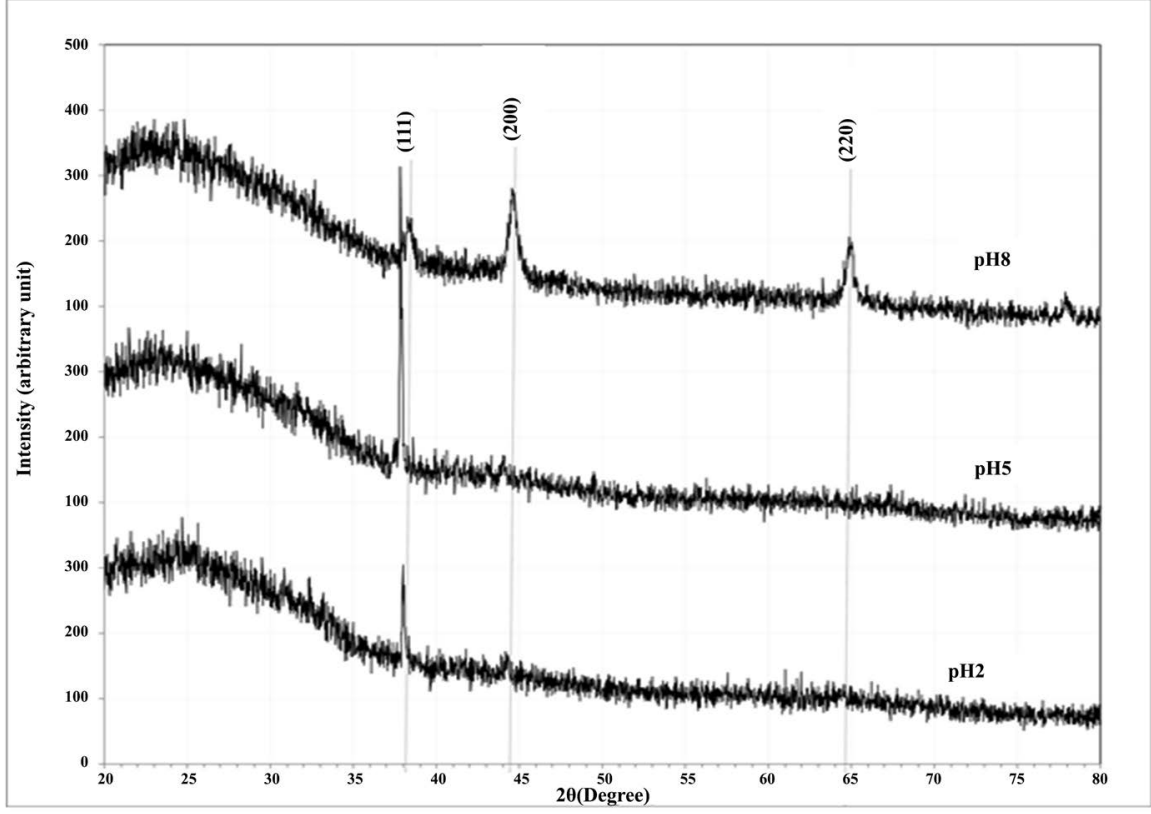

Figure 6. XRD spectrums of the Ag NPs synthesized by sonoelectrochemical of $\mathrm{Ag}_{2} \mathrm{SO}_{4}$ electrolyte at different $\mathrm{pH}$ value.

shows the presence of the diffraction peaks located at $38.35^{\circ}, 44.58^{\circ}$ and $64.8729^{\circ}$ corresponding to (111), (200) and (220) planes and identical with face centered cubic (fcc) structure (Card No. 96-901-3047) [11]. The peaks being broad, i.e. the crystalline size decrease, with decreasing electrolyte acidity (higher $\mathrm{pH})$ as shown in Table 1.

By comparing the grain size deduced from SEM and AFM images, with the crystallite size calculated from XRD spectrums using, Sheerer equation, the number of crystal in grain can be represented as the ratio between these two values [12], and the results are as follow: at $\mathrm{pH} 2=73 / 37.7=2$, at $\mathrm{pH} 5=63 / 16.1$ $=4$, and at $\mathrm{pH} 8=48 / 13.2=3.63$. 
Table 1. XRD parameters of the Ag NPs synthesized by sonoelectrochemical method at different $\mathrm{pH}$ values. (a) $\mathrm{pH} 2$; (b) $\mathrm{pH} 5$; (c) $\mathrm{pH} 8$.

\begin{tabular}{cccccccc}
\hline $\mathrm{pH}$ & $2 \theta($ Deg.) & $\begin{array}{c}\text { FWHM } \\
(\text { Deg.) }\end{array}$ & $\begin{array}{c}\mathrm{d}_{\mathrm{hkl}} \text { Exp. } \\
(\AA)\end{array}$ & $\begin{array}{c}\text { Crystallite } \\
\text { Size }(\mathrm{nm})\end{array}$ & $\mathrm{d}_{\mathrm{hkl}}$ Std. $(\AA)$ & $\mathrm{hkl}$ & card No. \\
\hline \multirow{2}{*}{2} & 37.9746 & 0.2230 & 2.3675 & 37.7 & 2.3723 & $(111)$ & $96-901-3047$ \\
& 44.1780 & 0.3559 & 2.0484 & 24.1 & 2.0545 & $(200)$ & $96-901-3047$ \\
& 37.8220 & 0.2990 & 2.3767 & 28.1 & 2.3723 & $(111)$ & $96-901-3047$ \\
& 44.0508 & 0.5339 & 2.0540 & 16.1 & 2.0545 & $(200)$ & $96-901-3047$ \\
& 38.3559 & 0.6356 & 2.3449 & 13.2 & 2.3723 & $(111)$ & $96-901-3047$ \\
8 & 44.5847 & 0.5339 & 2.0307 & 16.1 & 2.0545 & $(200)$ & $96-901-3047$ \\
& 64.8729 & 0.5593 & 1.4362 & 16.8 & 1.4528 & $(220)$ & $96-901-3047$ \\
\hline
\end{tabular}

\section{Conclusion}

Sono-electrodeposition of AgNPs was succeeded using $\mathrm{Ag}_{2} \mathrm{SO}_{4}$ electrolyte, decreasing the acidity of the electrolyte (higher $\mathrm{pH}$ ) in the range $\mathrm{pH} 2$ to 8 produced lower particle size of AgNPs.

\section{References}

[1] Mason, T.J. and Lorimer, J.P. (2002) Applied Sonochemistry: The Uses of Power Ultrasound in Chemistry and Processing. Willey-VCH, Weinheim.

[2] Sáez, V. and Mason, T.J. (2009) Sonoelectrochemical Synthesis of Nanoparticles. Molecules, 14, 4284-4299. https://doi.org/10.3390/molecules14104284

[3] Aqil, A., Serwas, H., Delplancke, J.L., Jerome, R., Jerome, C. and Canet, L. (2008) Preparation of Stable Suspensions of Gold Nanoparticles in Water by Sonoelectrochemistry. Ultrasonics Sonochemistry, 15, 1055-1061. https://doi.org/10.1016/j.ultsonch.2008.04.004

[4] Zin, V., Pollet, B.G. and Dabala, M. (2009) Sonoelectrochemical (20 kHz) Production of Platinum Nanoparticles from Aqueous Solution. Electrochimica Acta, 54, 7201-7206. https://doi.org/10.1016/j.electacta.2009.07.001

[5] Haas, I., Shanmugam, S. and Gedanken, A. (2006) Pulsed Sonoelectrochemical Synthesis of Size-Controlled Copper Nanoparticles Stabilized by Poly( $N$-Vinylpyrrolidone). Journal of Physical Chemistry B, 110, 16947-16952. https://doi.org/10.1021/jp064216k

[6] Atobe, M., Ishikawa, K., Asami, R. and Fuchigami, T. (2009) Size-Controlled Synthesis of Conducting Polymer Microspheres by Pulsed Sonoelectrochemical Polymerization. Angewandte Chemie International Edition, 48, 6069-6072. https://doi.org/10.1002/anie.200902062

[7] Zhu, J.-J., Qiu, Q.-F., Wang, H., Zhang, J.-R., Zhu, J.-M. and Chen, Z.-Q. (2002) Synthesis of Silver Nanowires by a Sonoelectrochemical Method. Inorganic Chemistry Communications, 5, 242-244. https://doi.org/10.1016/S1387-7003(02)00351-9

[8] Reisse, J., Francois, H., Vandercammen, J., Fabre, O., Kirsch-de Mesmaeker, A., Maerschalk, C. and Delplancke, J.-L. (1994) Sonoelectrochemistry in Aqueous Electrolyte: A New Type of Sonoelectroreactor. Electrochimica Acta, 39, 37-39. https://doi.org/10.1016/0013-4686(94)85008-9

[9] Qin, X., Miao, Z., Fang, Y., Zhang, D., Ma, J., Zhang, L., Chen, Q. and Shao, X. (2012) Preparation of Dendritic Nanostructures of Silver and Their Characterization for Electroreduction. Langmuir, 28, 5218-5226. 
https://doi.org/10.1021/la300311v

[10] Kumar, D., Bhui, H.B., Sarkar, P., Prasad, G., Sahoo, S.P. De, and Misra, A. (2009) Synthesis and UV-vis Spectroscopic Study of Silver Nanoparticles in Aqueous SDS Solution. Journal of Molecular Liquids, 145, 33-37.

https://doi.org/10.1016/j.molliq.2008.11.014

[11] MamtaBaunthiyal, K. and Singh, A. (2016) Characterization of silver Nanoparticles Synthesized Using Urticadioica Linn. Leaves and Their Synergistic Effects with Antibiotics. Journal of Radiation Research and Applied Sciences, 9, 217-227. https://doi.org/10.1016/j.jrras.2015.10.002

[12] John, R. and Florence, S. (2010) Optical Structural and Morphological Studies of Bean-Like ZnS Nanostructures by Aqueous Chemical Method. Chalcogenide Letters, 7, 269-273. 